\title{
An Intraparotid Schwannoma Mimicking A Warthin's Tumour
}

\section{Awan Z*, Azam A}

University Hospitals Birmingham NHS Foundation Trust, England.

*Corresponding author: Awan Z, University Hospitals Birmingham NHS Foundation Trust, England.

Received date: December 24, 2019; Accepted date: January 09, 2020; published date: January 14, 2020

Citation: Awan Z, Azam A (2020) An Intraparotid Schwannoma Mimicking A Warthin's Tumour. J Clinical Research and Reports, 2(2);

DOI: $10.31579 /$ jerr.2020/013

Copyright: (C) 2020 Awan Z. This is an open access article distributed under the Creative Commons Attribution License, which permits unrestricted use, distribution, and reproduction in any medium, provided the original work is properly cited.

\section{Abstract}

In this report, we describe the rare presentation of a cystic intraparotid facial nerve schwannoma (IPFNS) in a young female who initially presented with a painful unifocal parotid mass gradually enlarging over 5 years. Preliminary imaging and cytology offered this to be a Warthin's tumour. Here we describe the limitations of current diagnostic tools in the workup of intraparotid cystic lesions and highlight the importance of keeping rare tumours in mind to optimize pre--surgical management.

\section{Introduction}

Schwannomas are very rare, benign, slow--growing, encapsulated tumours of neuro-- ectodermal origin from neural sheath Schwann cells [1]. Approximately $30 \%$ of schwannomas occur in the head and neck with the majority being in the eighth nerve [2]. There is no clear sex predilection and peak incidence is between the third and sixth decade [3]. The aetiology is still not clear and no identifiable risk factors have been demonstrated thus far for solitary schwannomas however schwannomas may be seen in the autosomal dominant neurofibromatosis type 2 alongside at least one other nervous system tumour such as an acoustic neuroma, meningioma and glioma [4]. A facial nerve schwannoma (FNS) can occur at any point along its course from the cerebello--pontine angle to its peripheral branches [5]. In a review of 700 parotidectomies, Nussbaum observed only 1 case of FNS [6]. The IPFNS is an even rarer entitiy accounting for only $9 \%$ of schwannomas arising from the facial nerve itself [7]. The incidence of IPFNS is about 0.2 to $1.5 \%$ [8]. One retrospective study found that only 20 schwannomas out of 3722 involved the facial nerve of which 8 involved the intraparotid segment of the facial nerve [9]. Less than 100 cases of IPFNS have been reported in the literature.

As they are not a prioritized pre-operative diagnosis, they can lead to unintentional treatment errors and secondary intraoperative complications such as facial nerve palsy. Pre--operative diagnostic modalities such as an ultrasound scan (USS), magnetic resonance imaging (MRI) and fine needle aspiration cytology (FNAC) often narrow down the differentials when approaching parotid masses, aiding surgical excision. Most parotid tumours have characteristic cytomorphological features, which can be identified via the aforementioned modalities. Nonetheless because of the very few typical signs of IPFNS, interpretation can be difficult [10].

\section{Case:}

A 39 year old pregnant Pakistani female presented with a 5 year history of a painful enlarging right parotid mass. The patient denied any history of facial weakness or constitutional symptoms. She had an unremarkable past medical and family history and was not on any medications. On clinical examination, there was a tender, soft, mobile lump measuring approximately $20 \mathrm{~mm} \times 20 \mathrm{~mm}$. There were no signs of infection or associated lymphadenopathy and no evidence of facial nerve involvement. Laboratory tests including white cell count, C-reactive protein, viral serology and erythrocyte sedimentation rate were all within normal limits.

An initial USS of the salivary glands demonstrated a hypoechoic, $25 \mathrm{~mm}$, lobulated, thick--walled cyst, deeply embedded in the posterior part of the right parotid gland, lying posterior to the mandible (Figure $1)$. 


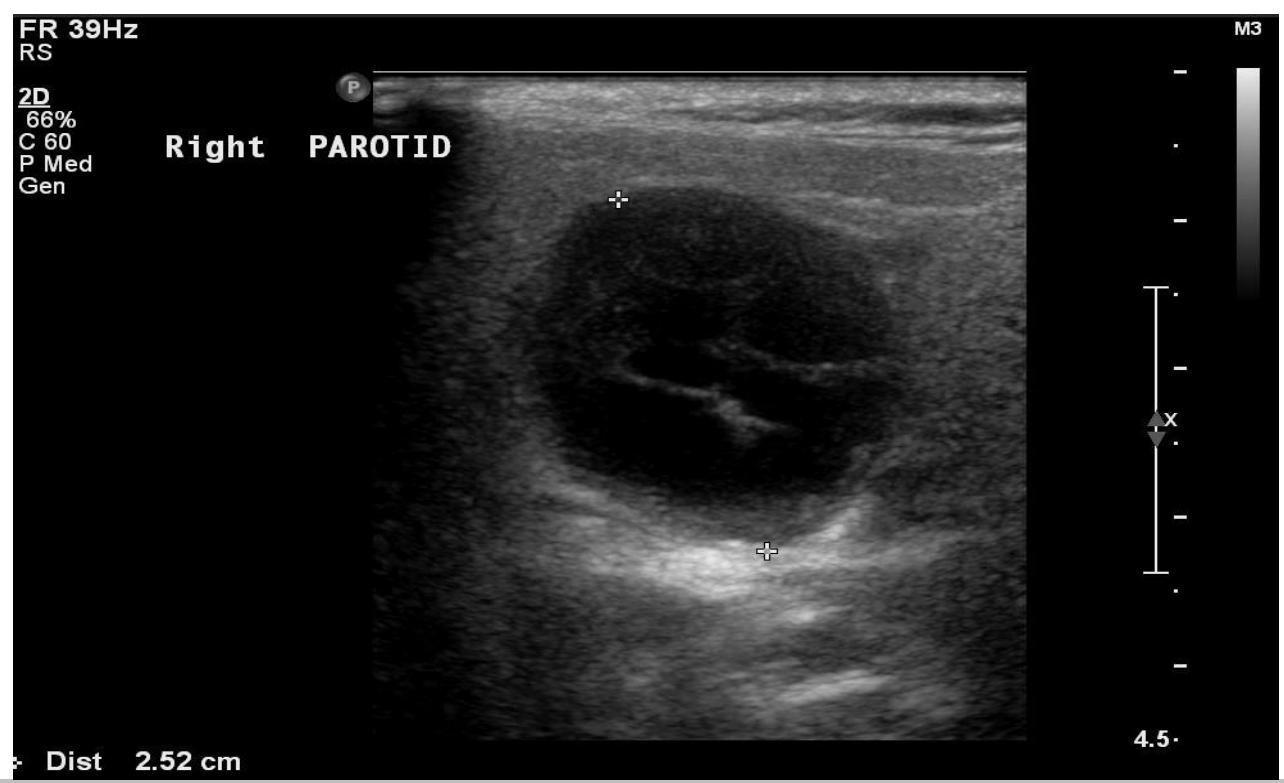

Figure 1: A markedly hypoechoic, well--circumscribed mass in the right parotid gland with no demonstrable internal vascularity representing a cyst with inspissated contents or a mixed solid and cystic lesion.

For further characterisation, MRI was performed during which period the pain had significantly worsened. This showed a well--defined predominantly cystic lesion measuring $22 \mathrm{~mm}$ x $22 \mathrm{~mm} \times 17 \mathrm{~mm}$ with low intensity T1 and high intensity T2 signals along the superficial and deep lobes of the right parotid, centering the retromandibular region. The solid components demonstrated contrast enhancement (Figure 2).

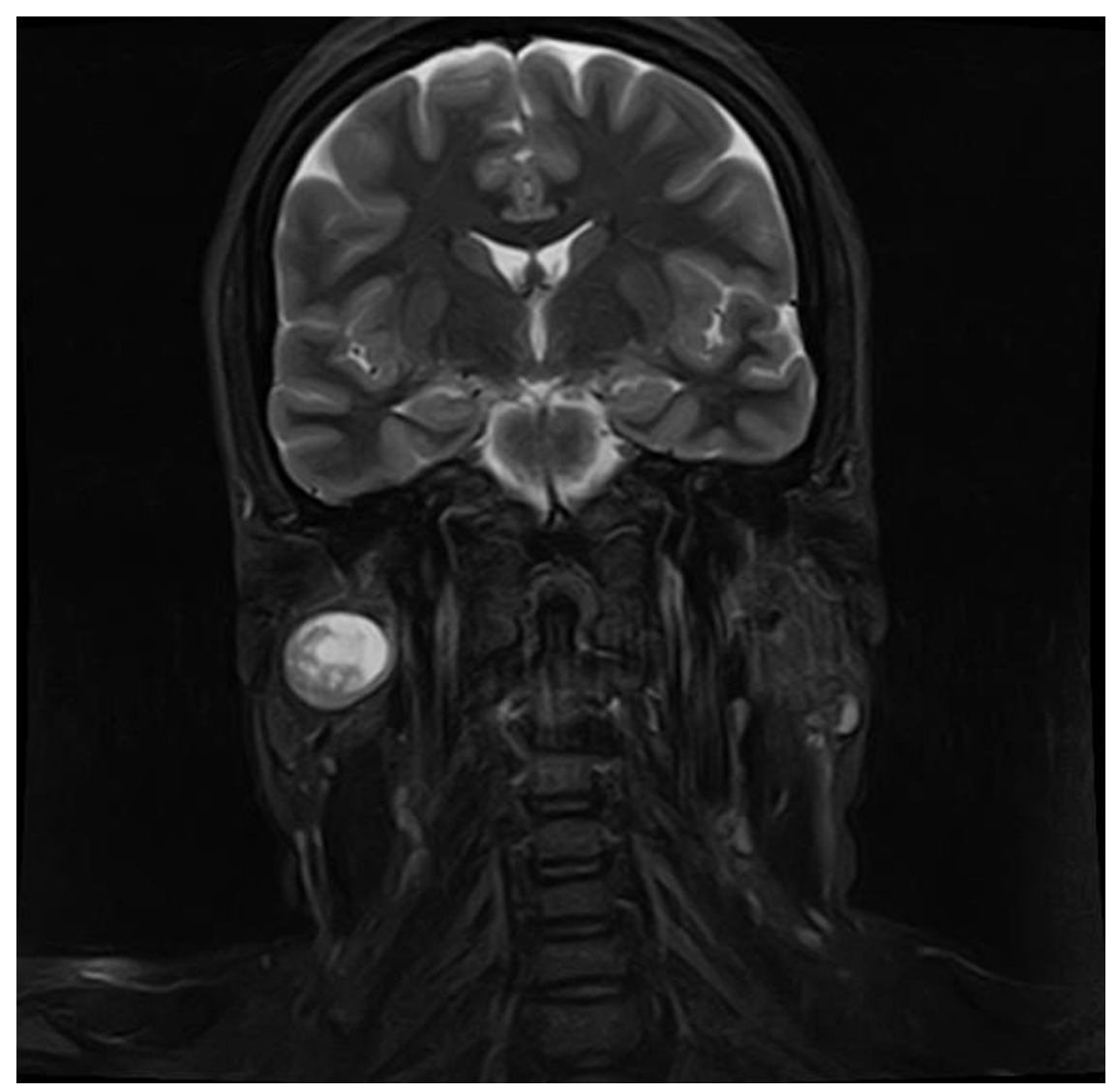

Figure 2: A well--defined predominantly cystic lesion. The solid components demonstrate contrast enhancement. 
A few normal--appearing intra-- parotid lymph nodes were noted with no enlarged or suspicious neck nodes. The conclusion was made of a benign or low--grade predominantly cystic tumour extending in to the deep lobe, most likely representing a Warthin's tumour. The patient subsequently underwent FNAC as she was pregnant and not willing to undergo surgery. Moreover, given the possibility of a low--grade possible malignancy which would have changed the management approach, invasive testing was required. The FNAC showed a benign lesion with cohesive sheets of oncocytic type cells and scattered lymphocytes in keeping with a Warthin's tumour. As the patient was pregnant, further intervention was postponed. Repeat MRI findings 16 months later were consistent with the previous scan however demonstrated an increase in size to $30 \times 22 \times 21 \mathrm{~mm}$.

The patient subsequently underwent a surgical resection of the mass on the preoperative MRI and FNAC conclusion of a symptomatic Warthin's tumour. The operation was difficult due to the fact that the cystic tumour appeared to be stuck to the facial nerve, possibly branching into the cyst wall. The cystic lesion burst with spillage into the wound. The surgery was completed with retrograde tracing of the branches of the facial nerve. Postoperatively, the patient sustained a right facial nerve dysfunction.

Histology later confirmed an intraparotid gland schwannoma of the facial nerve with cystic areas. On macroscopy, the cut surface showed a well--demarcated, white, firm nodule. Focal cystic changes with haemorrhage were noted with a surrounding rim of adipose tissue.

On microscopy, there was an encapsulated lesion with a predominance of Antoni A areas (Figure 3).

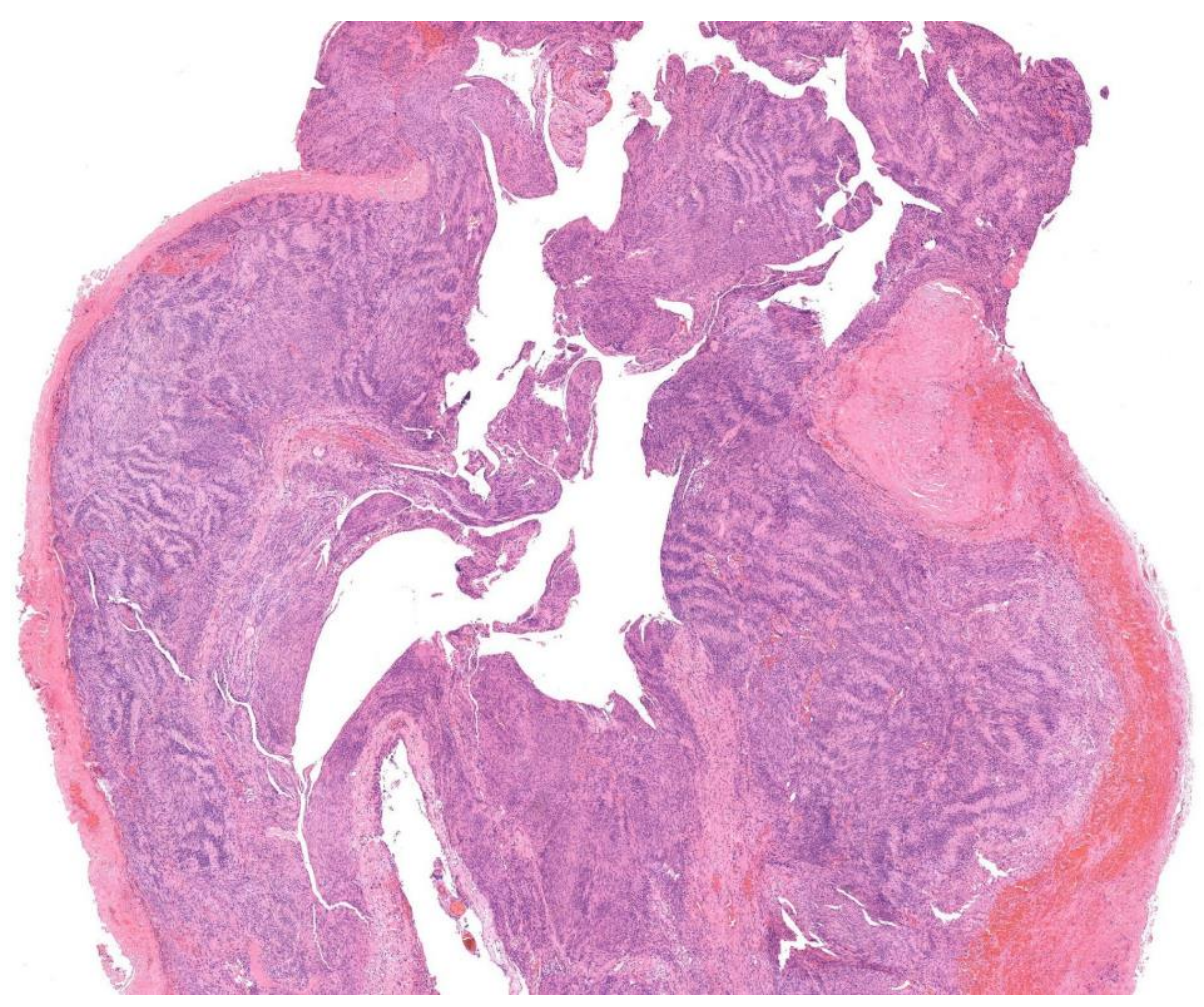

Figure 3: Hematoxylin \& Eosin Stain (x1 magnification). Encapsulated solid tumour composed of sheets of spindle cells forming Antoni A areas.

The solid areas comprised sheets of spindle cells with tapered bland nuclei. Characteristic nuclear palisading forming Verocay bodies and hyalinised blood vessels were also present (Figure 4). 


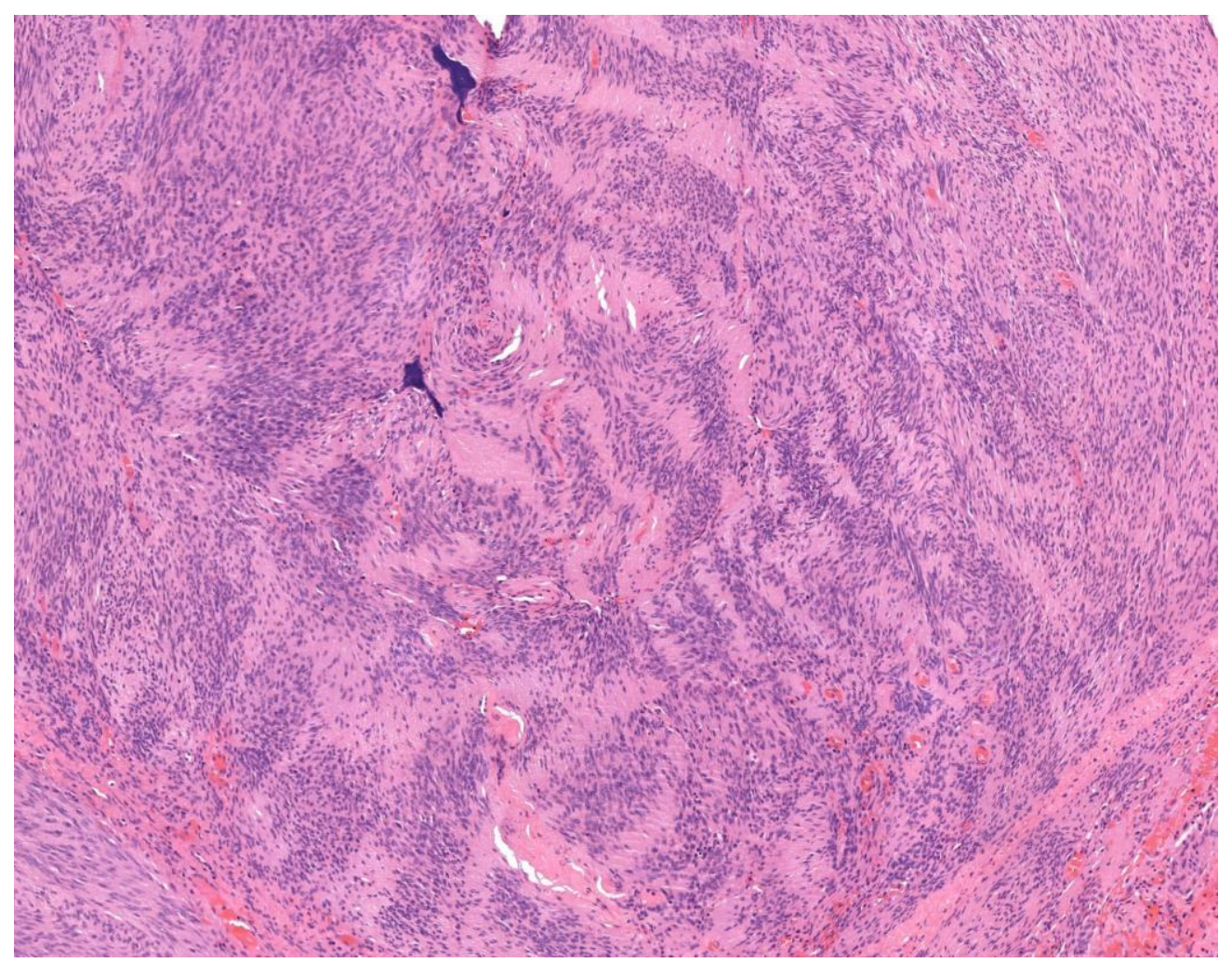

Figure 4: Hematoxylin \& Eosin Stain (x4 magnification). Evidence of characteristic Verocay bodies and hyalinised blood vessels. Cells are narrow, elongated and wavy with tapered ends interspersed with collagen fibers.

The cystic area showed a rim of macrophages with few lymphocytes, haemorrhage and cellular debris. There was no evidence of malignant changes ruling out the even rarer possibility of a malignant peripheral nerve sheath tumour (MPNST). A few small lymph nodes were also present which showed reactive changes. Completeness of excision was likely.

After discussion at the head and neck MDT, adjuvant treatment was not recommended. The patient was discharged with oral prednisolone, a 2-week outpatient review, a 12--month follow--up MRI, facial nerve rehabilitation and eye care. At the 12 month follow up appointment the patient's facial nerve function was gradually improving. A plan was made to discuss the option of nerve reanimation with the plastic surgeons.

\section{Discussion:}

IPFNS was first reported by Ibarz in 1927. It typically presents as a slow-growing, painless mass. Unusually, our patient presented with a painful mass. One literature review shows that more than $75 \%$ of IPFNS remain unknown until after surgery as in our case [11]. Nonetheless, the potential for a preoperative diagnosis of FNS is essential for treatment planning [12]. The most common differential diagnoses of cystic parotid masses include retention cysts, post--traumatic sialoceles, Warthin's tumour, mucoepidermoid carcinoma and necrotic metastases [13].

From an imaging point of view, there is no concrete evidence that any radiological method is superior [10]. In essence, there are no definitive radiological findings for IPFNS (14). In most reports, results are inconclusive or suggestive of a different pathology, as in our case. There have been several reports in which pre--histological diagnostic investigations have mistaken FNS for pleomorphic adenomas [10, 15]. MRI findings suggestive of FNS such as the 'string sign' and 'target sign' $[16,17]$ were not demonstrated in our case. Nonetheless, these findings are not specific and may be found in other neurogenic tumours such as neurofibroma and MPNST [10]. Moreover, a CT scan was not employed as previous authors [18] have emphasized that CT is not the ideal imaging modality for evaluation of parotid masses, primarily because soft tissue structures and the facial nerve are not well visualized. On the other hand, some authors have reported that a schwannoma that has undergone cystic degeneration will appear as a multilocular cystic structure with multiple, fine septations and solid areas, along with calcifications within the cyst walls on CT [19]. Given our histological findings, this may have been useful to compare. The general conclusion has been that a multitude of parotid tumours can display identical features on imaging thus, the heterogeneity of imaging features and the resulting broad differential diagnosis leads to very low rates of preoperative diagnosis [10].

The literature on the use of FNAC is inconclusive. Some report sensitivity and specificity as $60--100 \%$ and $90--100 \%$ respectively $[20,21]$ whereas others have found that FNAC is very often not diagnostic, and as in our case, can lend weight to an erroneous diagnosis due to lack of characteristic cytological findings and exact cell type [7,15, 22-- 25].

Cho et al overcame this difficulty by employing intra--operative frozen section studies to reach the correct diagnosis [26]. On the one hand, frozen section examination that has been performed intra--operatively is recommended for both diagnosis and exclusion of malignancy [5,27]. On the other hand, occasionally the schwannoma is mistaken for a fibrosarcoma leading to unwarranted radical surgery [28]. Yologlu et al have suggested the option of diffusion weighted images and apparent diffusion coefficients as having a potential role in delineating different parotid masses [29].

Mehta and Deschler agreed with the option of intraoperative conservative biopsy in a nonstimulating portion of the lesion to make a diagnosis [30]. Classification systems have been proposed based on variables such as House-- Brackmann grades, size, position and adherence of the mass with 
respect to the nerve to help guide intra--operative surgical approaches [23,31--33].

In a case such as ours, although the patient did not have a significant family history nor present with any audiovestibular or general neurological symptoms, it is pertinent to note the possible underlying diagnosis of neurofibromatosis type 2 in patients presenting with any schwannoma. If the suspicion is high, then the management plan should also incorporate imaging of the brain and a full neurological work up.

The management of intraparotid schwannoma has been a hotly contested issue within the recent literature, with some authors advocating conservative surveillance over surgical management for patients with minimal to no facial nerve dysfunction or tumor localized to the parotid gland without intratemporal extension [10,34]. Options include more limited resections (extracapsular dissection, partial lateral parotidectomy) versus more extensive and traditional options (lateral parotid lobectomy, total parotidectomy) [10]. Enucleation with nerve preservation is the preferred surgical option in order to optimize facial nerve function [35]. However, nerve excision with cable graft may also be performed [35]. Stereotactic radiosurgery shows promising preliminary results for treatment of intra--temporal FN schwannomas, which could possibly be applied to cases of IPFNS [36]. Other surgical options available in cases such as ours include a sural nerve interposition graft or a hypoglossal-facial nerve anastomosis as better results are obtained in young patients and when there is a short time interval between paralysis and reconstructive surgery [34,35]. Renrong et al performed stripping surgery in patients with a FNS showing complete removal in all 17 patients with facial nerve preservation in 12 [37]. Xiang et al demonstrated the long--term outcomes of near-- total removal of FNS were also favorable [38]. A recent study suggested a novel surgical option, namely intra--capsular enucleation using a microscope, which should also be a safe and reliable treatment for IPFNS [36]. Overall, if the mass cannot clearly be distinguished from the facial nerve pre or intra--operatively, most authors advise observation and follow--up, except in cases of severe facial nerve dysfunction and/or extension into the mastoid [12,30,35] as employed in this case.

Although schwannomas may be cystic or solid, the predilection of cystic schwannomas are for the central nervous system. The microcystic variant is more commonly seen in the gastrointestinal tract and rarely in subcutaneous tissues [39]. Nonetheless, cystic degeneration may be seen in any schwannoma, regardless of location. As far as we are aware, this is the first reported case of a cystic intraparotid schwannoma being mistaken for a Warthin's tumour using pre--operative diagnostic modalities. It is the interplay of the cystic nature of the tumour in this particular case and the wide differentials of more common cystic masses within the parotid that made the diagnosis more challenging. There is no agreed diagnostic method for the pre--surgical diagnosis of IPFNS [40]. Even on clinical examination IPFNS have no particular distinguishing features and do not usually present with facial nerve dysfunction. It is also unusual for IPFNS to present with pain as it did in our patient. The majority of IPFNS are only recognized intra--operatively as their features can sometimes be difficult to distinguish radiologically from more common parotid gland tumours. Moreover, FNAC is rarely employed in such circumstances. In our case this was due to the patient being pregnant, not wishing to undergo an operation and the need to exclude the likelihood of malignancy as the management approach is different for benign and malignant parotid masses. Unique to our case, the FNAC offered a distinct diagnosis of a more common parotid gland tumour (Warthin's tumour). Our case pivotally highlights the discrepancy between the radiological and FNAC findings to the intra--operative and final histological findings raising a) the limitations of the common pre-operative modalities available and $b$ ) the need to raise awareness of IPFNS in the differentials of cystic and/or solid intraparotid masses.
In summary, cystic intraparotid schwannomas are extremely rare and generally unsuspected. Due to their nonspecific features on imaging and FNAC, they have a tendency to be misdiagnosed preoperatively, highlighting the limitations and pitfalls of the current diagnostic pathway prior to surgery.

\section{Learning Points:}

1. Intraparotid facial nerve schwannomas may mimic common neoplastic salivary gland conditions on FNAC and imaging.

2. When approaching a unifocal, unilateral cystic parotid mass, in light of the pre--surgical diagnostic limitations, always keep in mind rare neuroectodermal tumours such as schwannomas due to the subsequent clinical consequences this may have on the patient's nerve function and recovery.

3. A painful unilateral parotid mass with or without facial nerve involvement may represent a schwannoma.

4. Further research is required in to new diagnostic tools and surgical options if surgeons encounter IPFNS.

\section{References:}

1. Bhaker P, Chatterjee D, Gochhait D et al. (2014) Schwannoma of the parotid gland: Diagnosis by fine--needle aspiration cytology. Journal of Cytology/Indian Academy of Cytologists. 31(4):196--198

2. Conley J and Janecka IP (1973) Neurilemmoma of the facial nerve. Plastic and Reconstructive Surgery. 52: 55-60

3. Putney FJ, Moran JJ and Thomas GK (1964) Neurogenic tumors of the head and neck. Laryngoscope. 74:1037-59

4. Stout AP (1949) Atlas of Tumor Pathology. Tumors of the Peripheral Nervous System. AFIP, Washington DC. Section II: 15$-16$

5. Damar M, Dinc AE, Elicora SS et al (2016) Facial Nerve Schwannoma of Parotid Gland: Difficulties in Diagnosis and Management. Case Reports in Otolaryngology.

6. Nussbaum M, Cho HT and Som ML (1976) Parotid space tumors of non-- salivary origin. Annals of Surgery.183:10-2

7. Balle VH and Greisen O. (1984) Neurilemmoma of the facial nerve presenting as parotid tumors. Annals of Otology, Rhinology and Laryngology.93(1):70-72

8. Sneige N and Batsakis JG (1991) Primary tumors of the facial (extracranial) nerve. Annals of Otology, Rhinology and Laryngology. 100:604--6

9. Caughey RJ, May M and Schaitkin BM. (2004) Intraparotid facial nerve schwannoma: diagnosis and management. Otolaryngology-Head and Neck Surgery.130(5):586-592

10. McCarthy WA and Cox LB. (2014) Intraparotid Schwannoma. Archives of Pathology and Laboratory Medicine. 138(7):982--985

11. Hakam N, Farag I and Philip G (2014) A case of schwannoma presenting as a benign parotid tumor. Egyptian journal of ear, nose throat and allied sciences. 15(3): 247--249.

12. Ma Q, Song H, Zhang P et al (2010) Diagnosis and management of intraparotid facial nerve schwannoma. Joural of Craniomaxillofacial Surgery. 38:271--3.

13. Avery AP and Sprinkle PM (1972) Benign intraparotid Schwannomas.Laryngoscope.82: 199--203

14. Martin N, Sterkers O, Mompoint D et al (1992) Facial nerve neuromas:MR imaging. Report of four cases. Neuroradiology.34:62--7.

15. Mair S and Leiman G (1989) Benign neurilemmoma (schwannoma) 
masquerading as a pleomorphic adenoma of the submandibular salivary gland. Acta Cytologica. 33(6):907--10.

16. Shimizu K, Iwai H, Ikeda K et al (2005) Intraparotid facial nerve schwannoma: a report of five cases and an analysis of MR imaging results. American Journal of Neuroradiology.26:1328--30.

17. Suh JS, Abenoza P, Galloway HR et al (1992) Peripheral (extracranial) nerve tumors: correlation of MR imaging and histologic findings. Radiology. 183(2):341--6

18. Lee YYP, Wong KT, King AD et al (2008) Imaging of salivary gland tumors.European Journal of Radiology. 66(3):419-436

19. Jindal T, Mukherjee S, Kamal MR et al (2013) Cystic schwannoma of the pelvis. Annals of the Royal College of Surgeons England. 95(1):1--2

20. Layfield LJ, Tan P and Glasgow BJ (1987) Fine--needle aspiration of salivary gland lesions. Comparison with frozen sections and histologic findings. Archives of Pathology and Laboratory Medicine.111:346-53

21. Shaha AR, Webber C, DiMaio T et al (1990) Needle aspiration biopsy in salivary gland lesions. American Journal of Surgery. 160: 373-6

22. Spiro RH (1991) Diagnosis and pitfalls in the treatment of parotid tumours. Seminars in Surgical Oncology. 7: 20-4

23. Alicandri--Ciufelli M, Marchioni D, Mattioli F et al (2009) Critical literature review on the management of intraparotid facial nerve schwannoma and proposed decision--making algorithm. European Archives of Otorhinolaryngology.266:475--9

24. Verma RK, Prasad RK, Bharti S et al (2011) Intraparotid facial nerve schwannoma involving the deep lobe: a case report. Egyptian Journal of Ear, Nose, Throat and Allied Sciences. 12(3):163--166

25. Cibas E and Ducatman B (2009) Cytology: Diagnostic Principles and Clinical Correlates. 3rd ed. Philadelphia, PA: Saunders Elsevier.

26. Cho HR, Kwon SS, Chung S et al (2014) Intraparotid Facial Nerve Schwannoma. Archives of craniofacial surgery. 15(1):28--31.

27. Angeli SI and Brackmann DE (1997) Is surgical excision of facial nerve schwannomas always indicated? Otolaryngology--Head and Neck Surgery. 117(6):144--147

28. Sullivan MJ, Babyak JW and Kartush JM (1987) Intraparotid facial neurofibroma, Laryngoscope. 97:219--223.
29. Yologlu Z, Aydin H, Alp NA et al (2016) Diffusion weighted magnetic resonance imaging in the diagnosis of parotid masses. Preliminary results. Saudi Medical Journal. 37(12) 1412--1416.

30. Mehta RP and Deschler MD (2008) Intraoperative diagnosis of facial nerve schwannoma at parotidectomy. American Journal of Otolaryngology. 29(2):126--129.

31. Marchioni D, Alicandri Ciufelli M and Presutti L (2007) Intraparotid facial nerve schwannoma: literature review and classification proposal. Journal of Laryngology and Otology. 121:707--12.

32. Bacciu A, Nusier A, Lauda L et al (2013) Are the current treatment strategies for facial nerve schwannoma appropriate also for complex cases? Audiology and Neurootology. 18(3):184--191.

33. Quer M, Poorten VV, Takes RP et al. (2017) Surgical options in benign parotid tumors: a proposal for classification. European Archives of Otorhinolaryngology. 1--12.

34. Gross BC, Carlson ML, Moore EJ et al (2012) The intraparotid facial nerve schwannoma: a diagnostic and management conundrum. American Journal of Otolaryngology.33(5):497-504

35. Salemis NS, Karameris A, Gourgiotis S et al (2008) Large intraparotid facial nerve schwannoma: case report and review of theliterature. International Journal of Oral Maxillofacial Surgery. 37:679--81.

36. Rigante M, Petrelli L, De Corso E et al (2015) Intracapsular microenucleation technique in a case of intraparotid facial nerve schwannoma. Technical notes for a conservative approach. Acta Otorhinolaryngolica Italica 35:49--52.

37. Lu R, Li S, Zhang L et al (2015) Stripping surgery in intratemporal facial nerve schwannomas with poor facial nerve function. American journal of otolaryngorology. 36(3):338--341.

38. Xiang D, Liu L, Li Y et al (2015) Near total removal of facial nerve schwannoma: longterm outcomes. American journal of otolaryngology.36(3):390--392.

39. Liegl B, Bennett MW and Fletcher CD (2008) Microcystic/reticular schwannoma: a distinct variant with predilection for visceral locations. American Journal of Surgical Pathology. 32(7): 1080--7.

40. Gumussoy M and Ekmekci S (2019) Intraparotid facial nerve schwannoma in a nine--year--old patient. Diagnosis, classification, and surgical approach stages. Journal of Craniofacial Surgery. 30(2):516--518

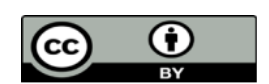

This work is licensed under Creative Commons Attribution 4.0 License

To Submit Your Article Click Here: Submit Article

DOI: $10.31579 /$ jcrr.2020/013
Ready to submit your research? Choose Auctores and benefit from:

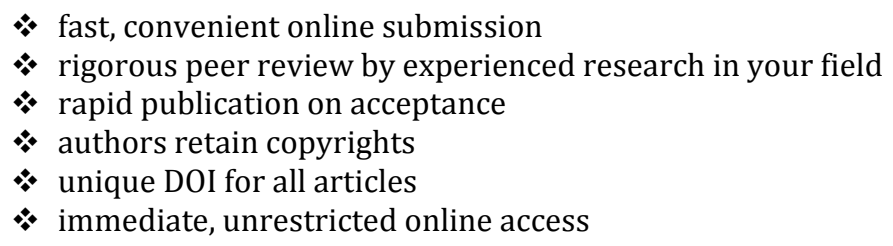

At Auctores, research is always in progress.

Learn more www.auctoresonline.org/journals/journal-of-clinical-researchand-reports 